\title{
Exploring Vertical Coherence of Content Topics in Philippine Spiral Kto10 Mathematics Curriculum
}

\author{
Ryan V. Dio \\ Sorsogon State College, Magsaysay Street, Sorsogon City, Philippines \\ https://orcid.org/0000-0002-4170-8828
}

\begin{abstract}
Vertical coherence of the content topics coupled with careful sequencing of learning competencies considering student's cognitive level of development has been identified as an excellent characteristic of a well-planned spiral progression approach of the curriculum. This descriptive-evaluative method of study tailored with the Discrepancy Evaluation Model (DEM) as a framework of analysis explored the Philippine Kindergarten to Grade 10 (Kto10) mathematics curriculum guide (CG) to determine the program strengths and areas that need improvement. The qualitative approach to the analysis of CG is supported by the feedbacks and experiences of 16 teacher-informants (3Male, 13Female). The curriculum mapping revealed that content topics were arranged in increasing complexity (though there were observed discontinuity) with the corresponding progression of mathematical tasks across the grade level. However, the spiral design of the curriculum failed to decongest the distribution of the content and learning competencies which became unrealistic to implement for general classrooms according to the level of cognitive development of Filipino learners as revealed by the feedbacks and experiences of mathematics teachers. The $\mathrm{K}$ to 10 Mathematics curriculum needs revision covering the most essential learning competencies (vertically arranged) per content area anchored on international benchmarks.
\end{abstract}

Keywords: Vertical Coherence; Philippine Kto10 Mathematics; Spiral Progression Approach; Curriculum Mapping; Discrepancy Evaluation Model

\section{Introduction}

The Philippine mathematics basic education curriculum content and standards underwent huge transformation (Verzosa \& Vistru-Yu, 2019; Morales, 2017; Okabe, 2013; Nebres, 2009), meeting the overarching demands and needs of the modern technological-based society attuned to the challenges of globalization (Ezeudu, Nkokelonye \& Adigwe, 2013; Vidali \& Adam, 2006). It is believed that changes and concrete reforms must be made to have a better system, and with a better system, a better future awaits (Musa \& Ziatdinov, 2012). On the other hand, 
any practice, which entails replacing material and redesigning curricula content may be detrimental to the students' future learning needs (Masters \& Gibbs, 2007).

The Philippine Mathematics Curriculum through the implementation of expanded K to 12 Basic Education program (6 years of Elementary level, 4 years Junior High School, 2 years Senior High School) with Kindergarten as entrance requirements follow the spiral progression approach to ensure mastery of knowledge and skills after each grade level that is at par with international standards. The curriculum is designed to decongest the distribution of content topics and competencies. In line with the National Council of Teachers of Mathematics (NCTM), principles and standards for school mathematics (NCTM, 2000) consist of five content areas grouped as Numbers and Number Sense, Measurements, Geometry, Patterns and Algebra, and Probability and Statistics which are learned from Kindergarten to Grade 10 ( $\mathrm{K}$ to 10 ) in increasing complexity.

Initiatives have been made so that mathematics basic education curriculum content in the Philippines is aligned with international standards. However, aside from NCTM standards, there are various international benchmarks each state needs to consider such as the Common Core State Standards for Mathematics (CCSSM), the Trends in International Mathematics and Science Study (TIMSS), the Program for International Student Assessment (PISA) standards among others. The Science Education Institute (SEI) of the Department of Science and Technology (DOST) and the Philippine Council of Mathematics Teachers Educators (MATHTED), Inc. has developed a mathematics framework as a comprehensive guide for the Philippine basic education sector (SEI-DOST \& MATHTED, 2011) parallel to the international benchmarks. This mathematics framework document served as an instrument in the creation of the Spiral Mathematics curriculum under the Philippine Enhanced Basic Education Act of 2013 (Republic Act [RA] 10533, 2013) otherwise known as Philippine K to 12 programs.

Accepting that curriculum initiatives are generally well-planned does not guarantee that the experience or that curriculum itself will be as intended by the planners (Hatzakis, Lycett \& Serrano, 2007). It was reported in several fora and studies that mathematics curricula tend to concentrate on the abstract concepts of mathematics rather than the application or discovery of concepts. This leads to students' perception of mathematics to be an irrelevant subject to the real world outside the classroom (Burghes \& Hindle, 2004; Smith, 2004). By not highlighting the practical applications of mathematics in the curriculum, teaching methods, and assessment, students are not challenged to develop higher-order thinking skills (Schoenfeld, 1988; Tanudjaya \& Doorman, 2020). The current study assessed the consistency of competencies across grade level towards the deepening of students' mathematics skills along with the required performance standards as an important indicator in the attainment of quality mathematics education.

The Philippine's twin goals of mathematics education in producing a mathematically empowered citizenry (SEI-DOST \& MATHTED, 2011) are the 
development of critical thinking and problem-solving skills of learners (Department of Education [DepEd], 2016). These twin goals are to be achieved with an organized and solid mathematics content, the development of strong cognitive skills expressed in terms of performance or process standards, and the promotion of desirable cognitive values with the use of appropriate educational technologies. The emphasis of performance and/or process standards such as estimating, computing and solving; visualizing and modeling; applying and connecting among others is in consonance to the adoption of the outcomes-based principles as well as revised blooms cognitive taxonomy (Ari, 2011; Amer, 2006) where learners are expected to produce products at the end of the term or grade level.

The Philippine $\mathrm{K}$ to 10 Mathematics Curriculum Guide expounded that the curriculum provides necessary mathematics concepts and life skills needed by Filipino learners as they proceed to the higher stages of learning (DepEd, 2016). The present investigation is concerned with the analysis of how the content topics and learning competencies in the current curriculum are sequentially arranged along with the mathematics content areas across grade levels in consonance with the spiral progression approach. Drew (2020) expounded Bruner's spiral curriculum as an approach to education that involves regularly re-visiting the same educational topics throughout a student's education. The importance of the careful arrangement of topics and competencies in a spiral progression approach has been expounded in several studies (Castillo, 2014; Briggs \& Peck, 2015) to achieve the expected learning outcomes in each grade level. In a spiral progression approach, previous knowledge and skills acquired by the students in the previous lessons (Schema Theory) are essential in building up new knowledge and skills connected to the next lesson (Harden, 1999; Capilitan, Cabili \& Sequete, 2015; Drew, 2020).

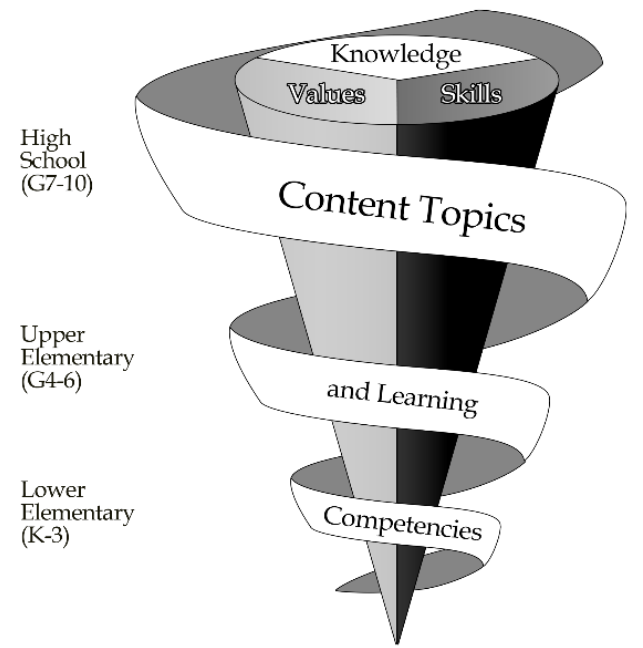

Figure 1. Spiral Curriculum Content Topics and Learning Competencies

The value of the spiral curriculum lies in the provision of continuing reinforcement and learning activities arranged from simple to complex manner of deepening skills to reach higher-level objectives and application of the acquired 
knowledge in a flexible learning environment (Harden, 1999). The spiraling of the learning content and competencies broaden as the students' pass-through highergrade level which requires mastery of the foundational knowledge, values, and skills as illustrated in Figure 1. It can be linked to the idea that any complex material can be learned by anybody if properly structured and presented. It is, therefore, necessary to review the vertical continuity of the current Philippine spiral mathematics curriculum content and competencies across grade levels to yield a better outcome.

A vertically coherent set of learning competencies and standards is essential in implementing the spiral progression approach of the curriculum. Vertical coherence refers to the set competencies taught to students in one lesson, course, or grade level that prepares them for the next level of study with higher competencies. Curriculum mapping which aims to establish vertical coherence ensures that teaching is purposely structured and logically sequenced across grade levels so that students are building on what they have previously learned that will progressively prepare them for more challenging, higher-level work (Schweitzer, 2020; Van den Akker, 2004).

However, Snider (2004) described that the spiral design found in most of the textbooks, where many topics are covered, does not promote mastery of fundamental mathematical concepts on which higher-level mathematics is built. The spiraled curriculum tends to revisits almost all the content of the previous year (Jensen, 1990) for which students lose ground in mathematics as they progress into middle and high school levels based on the National and international assessment results (Snider, 2004).

In the Philippines, Mateo (2019) emphasized in an article that there are a lot of competencies and content that the students have to study in a limited time allotted for each grade level in the current $K$ to 12 mathematics basic education curriculum. His article also expounded that the $\mathrm{K}$ to 12 programs had an impact on the learning of students, bringing the Philippines to rank second lowest in mathematics and science out of 79 countries in the 2018 Program for International Student Assessment (PISA) apart from the low mastery in the Grade 6 and 10 Mathematics National Achievement Test (NAT) for the last three consecutive years (Albano, 2019).

This calls for the need to review and study the $\mathrm{K}$ to 12 programs as expressed by Senator Sherwin Gatchalian of the Republic of the Philippines (Casayuran, 2020; Ager, 2020) to achieve better results in the future assessments. This claim could be supported by the research commentary of Tran, Reys, Teuscher, Dingman and Kasmer (2016) on the necessity to conduct a careful and systematic analysis of the curriculum standards with due consideration to the expected level of cognitive demand at a particular grade level by assessing vertical coherence of the content topics and learning goals as a means in improving student learning outcomes. 


\section{Objectives of the Study}

The main purpose of the study was to explore the vertical coherence of the sequence of the content topics and the learning competencies of the Philippine $\mathrm{K}$ to10 spiral mathematics curriculum as a preliminary evaluation report. The study also deals with the identification of the strength and areas needing improvement of the spiraling features of the $\mathrm{K}$ to 10 Mathematics Curriculum.

\section{Methodology}

This descriptive-evaluative study utilized a qualitative approach to analysis in dealing with curriculum evaluation. The study adopted the features of curriculum evaluation defined by Glatthorn, Boschee and Whitehead (2005) focusing on the assessment of the vertical continuity of the learning competencies of the Philippine K to 10 Mathematics content area.

Bradley (1985) identified vertical curriculum continuity of content topics as one of the 10 indicators to measure the effectiveness of the developed curriculum. Moreover, the study also investigated the alignment of the content topics (CT) and learning competencies (LC) to the grade-level standards and over-all curriculum content standards as illustrated in Figure 2.

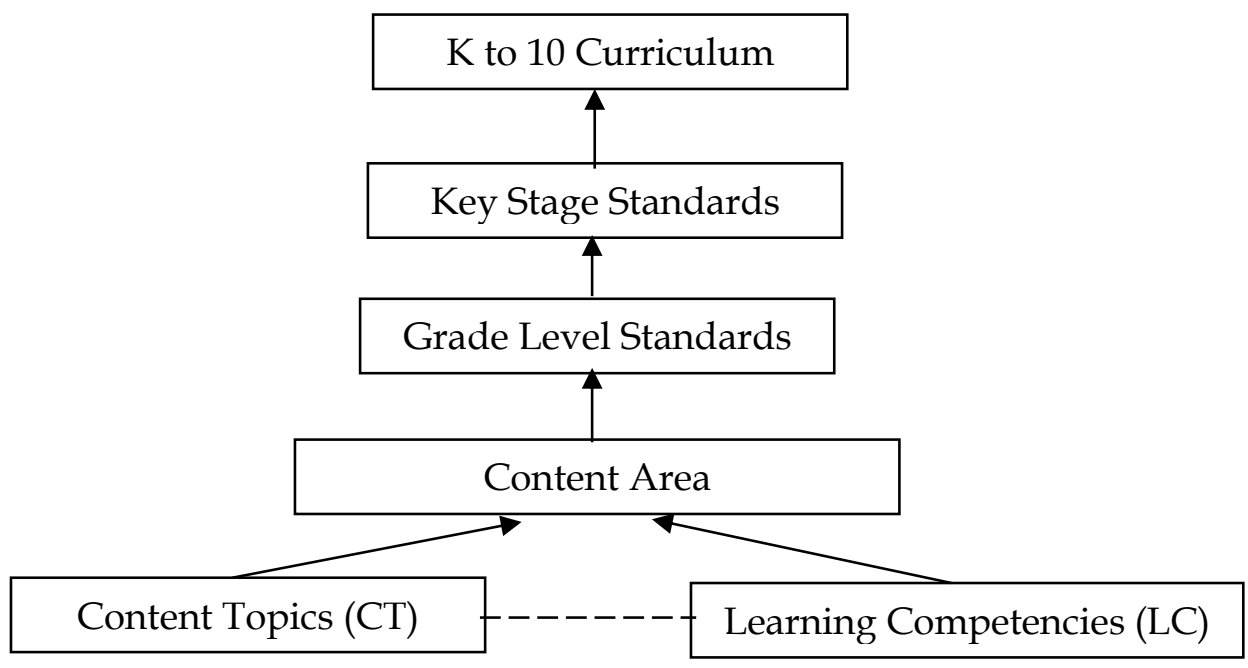

Figure 2. Vertical Alignment of Curriculum Standards

The Philippine K to 10 Mathematics Curriculum Guide (CG) served as an object of analysis in extracting information on the vertical coherence of curriculum standards as well as the multigrade sequence of learning experiences in the spiral progression approach. The framework of curriculum evaluation used in the study was tailored from the Discrepancy Evaluation Model (DEM) of Provus (1969) which is recognized as an ongoing cycle to provide information towards program assessment and improvement. It is assumed in this study that there is an existence of discrepancy in the expected output against the $\mathrm{K}$ to 10 mathematics curriculum standards based on the performances of the Filipino students in the national and international standardized test (Mateo, 2019; Albano, 2019; PISA, 2018). 
The curriculum evaluation in this study adopted the first stage of DEM analysis comprising the program design, input dimension, process dimension, and output dimension (Provus, 1969, p. 10) as a subject for improvement, maintenance, or termination. The study revolved on the following DEM steps adapted from the presentation of Ahmad (2011): (1) establish program design standards, (2) plan the evaluation, (3) implement plans to collect information, (4) identify discrepancies, and (5) plan what to do next.

\section{Step 1: Establishing Program Design Standards}

The study revisited the K to 10 Mathematics Curriculum standards using the CG to determine the content area standards and required CT and LC per grade level. The Key Stage Standards (KSS) clustered as Lower Elementary (Kindergarten to Grade 3 [Kto3]), Upper Elementary (Grade 4 to Grade 6 [G4to6]), and High School (Grade 7 to 10 [G7to10]) per content area of mathematics are extracted as a guide in the analysis on the vertical alignment of CT and LC across grade levels. Inventory of the CT and LC were also made to determine the content emphasis across grade levels and its alignment towards the attainment of the standards. The distribution of the CT and LC were presented using the frequency count and percentage against the total per content area.

\section{Step 2: Plan the Evaluation}

Curriculum evaluation in this study focuses on the written texts represented by the planned curriculum through CG analysis. The content analysis procedure of the CG was guided by the typology model of a qualitative approach to analysis (Suter, 2012a) to establish a vertically aligned curriculum standard. The evaluation led to the identification of the curricular strengths and the areas that need improvements showing the gaps and discrepancies on the established standards which were strengthened by the teachers' feedbacks and experiences. Teachers' feedbacks and experiences were determined through the combination of guided face-to-face, electronic, and questionnaire interviews.

\section{Step 3: Implementing Plans to Collect Information}

The implementation of the CG content analysis is supported by the analysis of teachers' experiences in the classroom to check consistency and stakeholder agreement of the findings. Each LC and CT were coded and grouped according to the content area across grade level ( $\mathrm{K}$ to 10$)$ in consonance to the Mathematics Framework for Philippine Basic Education (SEI-DOST \& MATHTED, 2011).

The content analysis of the DepEd CG was facilitated through curriculum mapping in assessing the alignment of $\mathrm{CT}$ and LC across grade levels. The $\mathrm{CT}$ was based on the list of topics set as reflected in the Mathematics Framework for Philippine Basic Education consists of CT strands with the corresponding subtopics. The LC was based on the list of specific competencies per content area found in the CG which were grouped according to the specific mathematics skills and values such as estimating, computing, modeling, communicating, proving, reasoning, appreciating among others representing the key LC. Shilling (2013) expounded the benefits and opportunities of curriculum mapping as a process of locating academic gaps, redundancies, and misalignment in the learning 
competencies, content topics, and performance standards to improve the overall coherence of a course of study across grade levels.

Assessment of the vertical coherence of CT and LC was the aim of curriculum mapping across grade levels in this study. Curriculum mapping which aims to assess vertical coherence ensures that topics and set of learning competencies are logically arranged across grade levels so that students are building up new knowledge and skills based on what they have previously learned that will progressively prepare them for a more challenging task.

On the other hand, teachers' feedbacks and experiences in implementing the $\mathrm{K}$ to 10 curricula were identified through the interview with the use of an open-ended question guide among the purposively selected 16 in-service basic education teacher-informants (3Male, 13Female) who are generally new (10 with less than 5 years teaching experience, three with 5-10 teaching experience, and another three with more than 10 years) in the service and residing in Bicol Region, Philippines. These identified teacher participants of the study were the only pre-selected informants who expressed their intention to take part in the entire research process through informed consent.

The information generated from feedbacks and experiences of teacher participants who implemented the $\mathrm{K}$ to 12 Mathematics program during their very first few years of teaching in the field were form part of the data validation of the study both for consistency checks and stakeholders' check (Suter, 2012b). They were selected to minimize any biases and comparison from their previous experiences of implementing the old curriculum which is unique in the study. The Philippine $\mathrm{K}$ to 12 curriculum which was signed into law through the Basic Education Act of 2013 (RA 10533, 2013) generates employment opportunities for teachers due to two years of addition in the basic education cycle since its first year of implementation in School Year 2012 to 2013. These hired teachers within seven years of implementing the $\mathrm{K}$ to 12 programs in the Philippines were the targeted respondents of the study to support them with their issues and concerns in attaining the standards (Luft, Dubois, Nixon \& Campbell, 2014) of implementing spiral mathematics curriculum which was further validated by the experiences, expertise, and observations of the three selected Master Teachers.

There were key interview questions utilized in the conduct of the study to show the experiences, issues, and concerns of the mathematics teachers. The following key questions were asked during the interview: (a) How do you describe yourself when you first started teaching the Kto12 curriculum? (b) How was your teaching environment then? (c) How are the contents of the Mathematics subject taught in the Grade level you are teaching]? (d) Do you have some issues and concerns in the implementation of the Mathematics curriculum [Please specify]? (e) In what way have you overcome the challenges that teaching $\mathrm{K}$ to 12 curricula entail? (f) What are your suggestions for improvement which may eventually minimize the occurrence of the problems you encountered? Follow-up questions were then given to expound on the idea and deepen the analysis of the details. 


\section{Step 4: Identify Discrepancies}

In step 4, curriculum mapping was utilized in this study as a technique to determine whether there is an existence of discrepancies, gaps, or issues on continuity in the standards and competencies (Hale, 2008; Jacobs, 2004; Jacobs \& Johnson, 2009) which hinders the smooth implementation of the spiral curriculum design. Various matrices (rows $=\mathrm{CT} / \mathrm{LC}$; and columns $=$ grade level) were made to enable and visualize the intention of curriculum mapping on vertical continuity or coherence as well as discrepancies per mathematics content area of Numbers and Number Sense (NS), Measurements (ME), Geometry (GE), Patterns and Algebra (AL), and Probability and Statistics (PS). Some portion in the implementation of the evaluation plan (Step 3) overlaps with the discrepancy identification (step 4) at this stage of DEM. Data generated from documents and teacher experiences were coded to categorized the curricular strengths and areas needing improvements.

\section{Step 5: Plan What to Do Next}

The final step of the DEM as an adopted framework for analysis provides ground for the maintenance, improvement, or termination of the program based on the identified strengths and discrepancies of the curriculum design.

\section{Results and Discussion}

The KSS of the Philippine Spiral Mathematics Basic Education Curriculum

The KSS as shown in Table 1 reflects the curriculum content and LC across grade levels per NS, ME, GE, AL, and PS content areas beginning in kindergarten. The analysis of the KSS of Mathematics Basic Education Curriculum grouped into three clusters: Lower Elementary (Kto3), Upper Elementary (G4to6), and High School (G7to10) extracted the standards for the five identified content areas of Mathematics. With the spiral curriculum design, the basic ideas, and foundational skills in mathematics are required to be introduced in the Lower Elementary (Kto3) and are reinforced and deepened in the higher-grade levels.

Numbers and Number Sense (NS). Along NS content area, the K to 3 learners are expected to demonstrate an understanding of the counting numbers (including reading, writing, and ordering) together with the fundamental operations through personal experience and hands-on activities in counting, sorting, and measuring which develop an understanding of the relative size, equivalent forms of numbers, and the use of numbers in representing real-world objects and quantities as applied in solving simple problems such as money. The learners are also introduced to the conceptual understanding of fractions (includes reading, writing, ordering) with the introduction of the concept of prime and composite numbers, factors, and multiples as well as the Roman Numerals towards the end of the K to 3 stages. Since the NS served as the foundational knowledge and skills in $\mathrm{K}$ to 10 Mathematics, it has the highest number and percentage share of key competencies and sub-LC among the content areas at this stage as reflected in Table 2. The learners are also exposed to repetitive drills and practice to learn when to use and how to use the four fundamental operations as they exhibit flexibility and critical thinking in solving simple problems towards the end of this stage, Grades 2 to 3, with the highest number of sub-CT when compared to other content areas as shown in Table 3. 
Students in the upper elementary grades (G4 to 6) are expected to demonstrate mastery of the operations of whole numbers using a more efficient and practical algorithm. Students at this stage are introduced to the fundamental operations of fractions and decimals (includes the meaning, reading, writing, ordering, estimation) as well as the order of operations as applied to real-world situations. The concept of base, exponents and scientific notations, percent, ratio and proportion, and integers are also introduced towards the end of the upper elementary stage, G5 to 6, which accumulated the highest number and percentage share of LC and CT of NS as exhibited in Tables 2 and 3.

Table 1. The KSS of Mathematics Content Area

\begin{tabular}{|c|c|c|c|}
\hline \multirow{2}{*}{$\begin{array}{l}\text { Content } \\
\text { Areas }\end{array}$} & \multicolumn{3}{|c|}{ Key Stage Standards } \\
\hline & Lower Elementary ( $\mathrm{K}$ to 3 ) & Upper Elementary (G 4 to 6) & Junior High School (G 7 to 10) \\
\hline $\begin{array}{l}\text { Numbers and } \\
\text { Number Sense } \\
\text { (NS) }\end{array}$ & $\begin{array}{l}\text { Demonstrate an understanding of } \\
\text { number notation, place value, } \\
\text { comparing and ordering whole } \\
\text { numbers up to } 10000 ; \text { operations and } \\
\text { properties of whole numbers applied } \\
\text { to problem-solving, Roman numerals; } \\
\text { identification of money value and } \\
\text { solving money problems; and the } \\
\text { concepts, simplifying, and ordering } \\
\text { fractions. }\end{array}$ & $\begin{array}{l}\text { Demonstrate an understanding of some } \\
\text { number theory concepts such as GCF } \\
\text { (greatest common factor) and LCM (least } \\
\text { common multiple) and the series of } \\
\text { operations of numbers; mastery of the } \\
\text { operations of whole numbers, fractions, } \\
\text { and decimals; understanding and } \\
\text { solving problems involving ratio, } \\
\text { proportion and percent; and } \\
\text { understanding of the concepts of } \\
\text { integers, exponents, base and scientific } \\
\text { notation. }\end{array}$ & $\begin{array}{l}\text { Demonstrate an understanding of } \\
\text { the key concepts of sets, the real } \\
\text { number system, estimation/ } \\
\text { approximation of a square root of a } \\
\text { number and the measures of } \\
\text { quantities, and the applications of } \\
\text { real numbers to measurements. }\end{array}$ \\
\hline $\begin{array}{l}\text { Measurement } \\
(\mathrm{ME})\end{array}$ & $\begin{array}{l}\text { Demonstrate an understanding of the } \\
\text { concept, application, and use of } \\
\text { standard and non-standard units in } \\
\text { measuring time, length, mass, area, } \\
\text { and capacity. }\end{array}$ & $\begin{array}{l}\text { Demonstrate an understanding of } \\
\text { measurements to approximate and } \\
\text { compute for the perimeter, circumference, } \\
\text { area of plane figures, surface area and } \\
\text { volume of solid figures, capacity, and } \\
\text { temperature. }\end{array}$ & $\begin{array}{l}\text { Continue to deepen their } \\
\text { understanding of the different types } \\
\text { of measures as they apply them in } \\
\text { problem-solving that involves } \\
\text { measurements such as perimeter, } \\
\text { area, weight, time, speed, } \\
\text { temperature, volume/ capacity, and } \\
\text { utility usage (meter reading). }\end{array}$ \\
\hline Geometry (GE) & $\begin{array}{l}\text { Demonstrate an understanding of the } \\
\text { basic properties of } 2 \mathrm{D} \text { and } 3 \mathrm{D} \text { shapes } \\
\text { through identifying, classifying, and } \\
\text { constructing figures including } \\
\text { tessellations and symmetry through } \\
\text { the use of appropriate educational } \\
\text { tools in hands-on or manipulative } \\
\text { activities and informal discussions. }\end{array}$ & $\begin{array}{l}\text { Demonstrate an understanding of angles } \\
\text { and lines relationship, symmetry, } \\
\text { polygons up to } 10 \text { sides, circles, and its } \\
\text { parts, and 2D representations of a 3D } \\
\text { solid figure }\end{array}$ & $\begin{array}{l}\text { Demonstrate an understanding of } \\
\text { the axiomatic development of } \\
\text { geometry, triangle congruence, } \\
\text { triangle and quadrilateral similarity } \\
\text { and inequalities, and the } \\
\text { applications of measurements in } \\
\text { geometric figures. }\end{array}$ \\
\hline $\begin{array}{l}\text { Patterns and } \\
\text { Algebra (AL) }\end{array}$ & $\begin{array}{l}\text { Demonstrate an understanding of } \\
\text { patterns, relationships, and sequence } \\
\text { on numbers, operations, and } \\
\text { geometric objects. }\end{array}$ & $\begin{array}{l}\text { Demonstrate an understanding of } \\
\text { patterns and number sentences, algebraic } \\
\text { expressions in one variable, and simple } \\
\text { equations. }\end{array}$ & $\begin{array}{l}\text { Demonstrate an understanding of } \\
\text { sequences, algebraic expressions, } \\
\text { variations, relations and functions, } \\
\text { inequalities in one and two } \\
\text { variables, and basic concepts of } \\
\text { trigonometry. }\end{array}$ \\
\hline $\begin{array}{l}\text { Statistics and } \\
\text { Probability (PS) }\end{array}$ & $\begin{array}{l}\text { Demonstrate an understanding of the } \\
\text { data collection, organizing data } \\
\text { through graphs, charts, or tables and } \\
\text { the idea of the likelihood of the event } \\
\text { to happen with the use of appropriate } \\
\text { educational tools in various designed } \\
\text { learning activities such as purposeful } \\
\text { play and manipulatives. }\end{array}$ & $\begin{array}{l}\text { Demonstrate an understanding of } \\
\text { organizing and interpreting data using } \\
\text { tables, bar graphs, line graphs, or circle } \\
\text { graphs and predicting outcomes of } \\
\text { experiments. }\end{array}$ & $\begin{array}{l}\text { Demonstrate an understanding of } \\
\text { the importance of the processes of } \\
\text { statistics, measures of central } \\
\text { tendencies, measures of variability, } \\
\text { measures of position, and basic } \\
\text { combinatorial concepts and } \\
\text { probability. }\end{array}$ \\
\hline
\end{tabular}

The KSS along NS content at the High School level (G7 to10) are expected to provide the learner a deeper understanding of the set of real numbers (whole numbers, integers, rational numbers, irrational numbers) as applied to measurements. Tables 2 and 3 displayed that KSS at this stage on the NS content area is expected to demonstrate the set of LC along with the CT by the learners at 
the end of Grade 7. The KSS on NS illustrates that integration of the concepts within, between, and among the content areas are strengthened at this stage such as learning the base, exponents, square roots among others which also could be learned in AL content areas. The high school students will learn that there are decimal numbers which are under the set of rational numbers (numbers which could be written in the form of $\frac{a}{b}$ ) and under the set of irrational numbers (decimals which are non-terminating non-repeating decimals) which help describe the roots of equations such as $x^{2}-5=0$ and in predicting results of $\sin \frac{\pi}{3}$ under AL content area.

Measurements (ME). The ME content focuses on finding, estimating, and comparing actual measurements of objects or events using real tools of standards and non-standard units of measures. The $\mathrm{K}$ to 3 learners begin with using nonstandards units in comparing objects or sets of objects which are longer or shorter, heavier or lighter, warmer or colder, quicker or slower, greater or lesser, and later on (towards the end of this stage, Grade 3) with the use of standard units of measurement. The learners at this stage will learn to choose appropriate units and tools to measure physical attributes as they develop critical thinking, making connections, and appreciation of the applications of measurements in daily life. Table 3 shows that most of the CT of ME is placed under lower elementary (Kto3) with the highest number and percentage share (about 4 to 5 content strand, and 9 to 10 sub-topics) among the five content areas. The learners will be exposed to a more experimental approach of learning when they reach the Upper Elementary stage (G4 to6) in approximating and computing for the perimeter, circumference, area of plane figures, surface area and volume of solid figures, capacity, and temperature with the use of appropriate tools. The ME content area has the highest number of key learning competencies across grade level in Grade 7 as shown in Table 2 to deepen student understanding of the different types of measures. Students at this stage are expected to apply and integrate their ME knowledge, skills, and values acquired in problem-solving with other disciplines such as physics, chemistry, biology, social sciences, economics, and livelihood education.

Geometry (GE). The GE content area KSS is progressively exhibited by the K to 3 learners through exposure to manipulative activities of sorting things, measuring, classifying models, constructing figures including tessellations and symmetry as they build the skill to make sense of the real world. The G4 to 6 learners will be exposed to more formal use of geometric terms in appreciating and understanding angles and lines relationship, symmetry, polygons, circles, and solid figures through explorations and experimentations. Learners are exposed to most of the lessons and LC in GE when they reach the upper elementary (G4to6) stage, see Tables 2 and 3. The High School learners will continue to investigate, give proof, and solve problems in deepening their knowledge and skills as well as the appreciation of the geometric shapes, congruence, similarity and inequalities, and the applications of measurements. The focus of geometry in high school is the analysis of the plane figure properties and the use of mathematical arguments and reasoning as applied in solving routine and non-routine problems to produce analytical and critical thinker graduates. 
Patterns and Algebra (AL). The AL content area highlights the patterns and relationships of quantities represented by variables used to generalize and model real situations. The $\mathrm{K}$ to 3 learners will learn and appreciate patterns, relationships, and sequence on numbers, operations, and geometric objects as they develop representations skills with the use of appropriate technology in experiential and hands-on activities. The G4 to 6 learners will be exposed to a variety of learning activities on generalizing, representations, and modeling of quantitative changes to learn patterns and number sentences, algebraic expressions in one variable, and simple equations. Learners of elementary level are expected to acquire the foundational knowledge, skills, and values of AL needed in more challenging LC along with the CT when they reach high school.

Table 2. Distribution of the K to10 Mathematics Learning Competencies (LC)

\begin{tabular}{|c|c|c|c|c|c|c|c|c|c|c|c|c|c|}
\hline \multirow{2}{*}{$\begin{array}{l}\text { Grade } \\
\text { Level }\end{array}$} & \multirow[b]{2}{*}{ LC } & \multicolumn{10}{|c|}{ Content Area } & \multicolumn{2}{|c|}{ Overall } \\
\hline & & \multicolumn{2}{|c|}{ NS } & \multicolumn{2}{|c|}{ ME } & \multicolumn{2}{|c|}{ GE } & \multicolumn{2}{|c|}{$\mathbf{A L}$} & \multicolumn{2}{|c|}{ PS } & \multirow[b]{2}{*}{25} & \multirow[b]{2}{*}{$(7 \%)$} \\
\hline K & Key LC & 13 & $(11 \%)$ & 4 & $(7 \%)$ & 2 & $(3 \%)$ & 5 & $(6 \%)$ & 1 & $(2 \%)$ & & \\
\hline \multirow{3}{*}{1} & Sub-LC & 29 & $(8 \%)$ & 15 & (13\%) & 9 & $(7 \%)$ & 11 & $(7 \%)$ & 2 & (3\%) & 66 & (8\%) \\
\hline & Key LC & 13 & $(11 \%)$ & 4 & (7\%) & 1 & $(1 \%)$ & 5 & $(6 \%)$ & 5 & (10\%) & 28 & $(8 \%)$ \\
\hline & $S u b-L C$ & 42 & $(11 \%)$ & 7 & $(6 \%)$ & 4 & $(3 \%)$ & 5 & (3\%) & 5 & $(6 \%)$ & 63 & (7\%) \\
\hline \multirow[t]{2}{*}{2} & Key LC & 17 & $(14 \%)$ & 6 & (11\%) & 4 & $(6 \%)$ & 4 & (5\%) & 5 & (10\%) & 36 & $(10 \%)$ \\
\hline & $S u b-L C$ & 60 & $(16 \%)$ & 18 & $(15 \%)$ & 8 & $(7 \%)$ & 3 & $(2 \%)$ & 5 & $(6 \%)$ & 94 & $(11 \%)$ \\
\hline \multirow[t]{2}{*}{3} & Key LC & 18 & $(15 \%)$ & 5 & $(9 \%)$ & 3 & $(4 \%)$ & 2 & (3\%) & 5 & (10\%) & 33 & (9\%) \\
\hline & Sub-LC & 63 & $(17 \%)$ & 12 & $(10 \%)$ & 7 & $(6 \%)$ & 4 & $(2 \%)$ & 5 & $(6 \%)$ & 91 & $(11 \%)$ \\
\hline \multirow[t]{2}{*}{4} & Key LC & 13 & $(11 \%)$ & 7 & $(13 \%)$ & 7 & $(10 \%)$ & 1 & $(1 \%)$ & 5 & $(10 \%)$ & 33 & (9\%) \\
\hline & $S u b-L C$ & 46 & $(12 \%)$ & 15 & $(13 \%)$ & 13 & $(11 \%)$ & 3 & $(2 \%)$ & 6 & $(8 \%)$ & 83 & $(10 \%)$ \\
\hline \multirow[t]{2}{*}{5} & Key LC & 19 & $(16 \%)$ & 8 & $(15 \%)$ & 9 & $(13 \%)$ & 1 & $(1 \%)$ & 6 & $(12 \%)$ & 43 & $(12 \%)$ \\
\hline & Sub-LC & 66 & $(17 \%)$ & 24 & (21\%) & 11 & $(9 \%)$ & 3 & $(2 \%)$ & 8 & (10\%) & 112 & $(13 \%)$ \\
\hline \multirow[t]{2}{*}{6} & Key LC & 13 & $(11 \%)$ & 9 & $(17 \%)$ & 10 & $(14 \%)$ & 7 & $(9 \%)$ & 5 & $(10 \%)$ & 44 & $(12 \%)$ \\
\hline & $S u b-L C$ & 52 & $(14 \%)$ & 20 & $(17 \%)$ & 7 & $(6 \%)$ & 14 & $(8 \%)$ & 8 & $(10 \%)$ & 101 & $(12 \%)$ \\
\hline \multirow[t]{2}{*}{7} & Key LC & 13 & $(11 \%)$ & 11 & $(20 \%)$ & 10 & $(14 \%)$ & 10 & $(13 \%)$ & 5 & $(10 \%)$ & 49 & $(13 \%)$ \\
\hline & $S u b-L C$ & 21 & $(6 \%)$ & 6 & $(5 \%)$ & 14 & (11\%) & 18 & (11\%) & 7 & $(9 \%)$ & 66 & $(8 \%)$ \\
\hline \multirow[t]{2}{*}{8} & Key LC & 0 & $(0 \%)$ & 0 & $(0 \%)$ & 10 & $(14 \%)$ & 19 & $(25 \%)$ & 6 & $(12 \%)$ & 35 & $(10 \%)$ \\
\hline & $S u b-L C$ & 0 & $(0 \%)$ & 0 & $(0 \%)$ & 21 & $(17 \%)$ & 40 & $(24 \%)$ & 10 & (13\%) & 71 & $(8 \%)$ \\
\hline \multirow[t]{2}{*}{9} & Key LC & 0 & $(0 \%)$ & 0 & $(0 \%)$ & 6 & $(9 \%)$ & 15 & (19\%) & 0 & $(0 \%)$ & 21 & $(6 \%)$ \\
\hline & $S u b-L C$ & 0 & $(0 \%)$ & 0 & $(0 \%)$ & 16 & $(13 \%)$ & 39 & (24\%) & 0 & $(0 \%)$ & 55 & $(6 \%)$ \\
\hline \multirow[t]{2}{*}{10} & Key LC & 0 & $(0 \%)$ & 0 & $(0 \%)$ & 7 & $(10 \%)$ & 8 & (10\%) & 6 & (12\%) & 21 & $(6 \%)$ \\
\hline & $S u b-L C$ & 0 & $(0 \%)$ & 0 & $(0 \%)$ & 12 & $(10 \%)$ & 25 & $(15 \%)$ & 23 & $(29 \%)$ & 60 & $(7 \%)$ \\
\hline \multirow{2}{*}{$\mathrm{K}$ to 10} & Key LC & 119 & & 54 & & 69 & & 77 & & 49 & & 368 & \\
\hline & $S u b-L C$ & 379 & & 117 & & 122 & & 165 & & 79 & & 862 & \\
\hline
\end{tabular}

The high school learners are expected to deepen their representational skills in various situations, transforming expressions, equations, or inequality into its simpler format, and to use the most appropriate strategies in finding a solution to a problem. The bulk of LC and CT of AL content area are placed in high school level with 10\%-25\% key competencies per grade level as illustrated in Table 2 and $24 \%-48 \%$ content strand of AL as shown in Table 3.

Statistics and Probability (PS). The PS content area focuses on data interpretation and analysis as well as making inferences, predictions, conclusions, and decisions 
from the given data set presented (tables, charts, and graphs) and collected. As early as lower elementary stage learners will begin to learn to record, read and interpret the displayed data as they realize that data can represent information through the use of appropriate educational tools in various designed appropriate learning activities.

The upper elementary learners start to simulate surveys and investigations to answer questions and problems objectively about organizing and interpreting data using tables and graphs as well as predicting outcomes of experiments. The high school learners continue to build their understanding of the different statistical measures and the basic combinatorial concepts and probability. Learners will be exposed to real-world data as they are made to realize the importance of baseline statistical information in decision making and problemsolving which are made available in today's technological society for easy accession. The PS content area has the least number of LC (79 out of 862 learning competencies) and CT (25 out of 269 topics) among the five-content area of Mathematics K to 10 Curriculum which is usually tackled in the last quarter of the school year.

Table 3. Distribution of Content Topics (CT) per Content Area of K to 10 Curriculum

\begin{tabular}{|c|c|c|c|c|c|c|c|c|c|c|c|c|c|}
\hline \multirow{2}{*}{$\begin{array}{l}\text { Grade } \\
\text { Level }\end{array}$} & \multirow[b]{2}{*}{ CT } & \multicolumn{10}{|c|}{ Content Area } & \multicolumn{2}{|c|}{ Overall } \\
\hline & & \multicolumn{2}{|c|}{ NS } & \multicolumn{2}{|c|}{ ME } & \multicolumn{2}{|c|}{ GE } & \multicolumn{2}{|c|}{ AL } & \multicolumn{2}{|c|}{ PS } & & \\
\hline \multirow[t]{2}{*}{$\mathrm{K}$} & Strand & 2 & $(20 \%)$ & 5 & (83\%) & 2 & $(40 \%)$ & 3 & $(14 \%)$ & 1 & $(20 \%)$ & 13 & $(28 \%)$ \\
\hline & Sub-Topic & 7 & $(11 \%)$ & 10 & $(43 \%)$ & 3 & $(6 \%)$ & 3 & $(3 \%)$ & 1 & $(7 \%)$ & 24 & $(9 \%)$ \\
\hline \multirow[t]{2}{*}{1} & Strand & 2 & $(20 \%)$ & 4 & $(67 \%)$ & 1 & $(20 \%)$ & 3 & $(14 \%)$ & 3 & $(60 \%)$ & 13 & $(28 \%)$ \\
\hline & Sub-Topic & 7 & $(11 \%)$ & 9 & (39\%) & 3 & $(6 \%)$ & 3 & $(3 \%)$ & 4 & $(16 \%)$ & 26 & $(10 \%)$ \\
\hline \multirow[t]{2}{*}{2} & Strand & 3 & $(30 \%)$ & 4 & $(67 \%)$ & 3 & $(60 \%)$ & 4 & $(19 \%)$ & 3 & $(60 \%)$ & 17 & $(36 \%)$ \\
\hline & Sub-Topic & 11 & $(18 \%)$ & 10 & (43\%) & 5 & $(10 \%)$ & 4 & $(4 \%)$ & 3 & $(12 \%)$ & 33 & $(12 \%)$ \\
\hline \multirow[t]{2}{*}{3} & Strand & 2 & $(20 \%)$ & 4 & $(67 \%)$ & 3 & $(60 \%)$ & 4 & $(19 \%)$ & 3 & $(60 \%)$ & 16 & $(34 \%)$ \\
\hline & Sub-Topic & 11 & $(18 \%)$ & 10 & $(43 \%)$ & 9 & $(18 \%)$ & 7 & $(6 \%)$ & 3 & $(12 \%)$ & 40 & $(15 \%)$ \\
\hline \multirow[t]{2}{*}{4} & Strand & 3 & $(30 \%)$ & 4 & $(67 \%)$ & 3 & $(60 \%)$ & 3 & $(14 \%)$ & 3 & $(60 \%)$ & 16 & $(34 \%)$ \\
\hline & Sub-Topic & 13 & $(21 \%)$ & 7 & $(30 \%)$ & 12 & $(24 \%)$ & 3 & $(3 \%)$ & 4 & $(16 \%)$ & 39 & $(14 \%)$ \\
\hline \multirow[t]{2}{*}{5} & Strand & 6 & $(60 \%)$ & 4 & $(67 \%)$ & 1 & $(20 \%)$ & 1 & $(5 \%)$ & 4 & $(80 \%)$ & 16 & $(34 \%)$ \\
\hline & Sub-Topic & 28 & $(45 \%)$ & 9 & (39\%) & 9 & $(18 \%)$ & 2 & $(2 \%)$ & 5 & $(20 \%)$ & 53 & $(20 \%)$ \\
\hline \multirow[t]{2}{*}{6} & Strand & 7 & $(70 \%)$ & 4 & (67\%) & 3 & $(60 \%)$ & 3 & (14\%) & 3 & $(60 \%)$ & 20 & $(43 \%)$ \\
\hline & Sub-Topic & 26 & $(42 \%)$ & 10 & $(43 \%)$ & 10 & $(20 \%)$ & 10 & $(9 \%)$ & 3 & $(12 \%)$ & 59 & $(22 \%)$ \\
\hline \multirow[t]{2}{*}{7} & Strand & 6 & $(60 \%)$ & 4 & (67\%) & 3 & $(60 \%)$ & 10 & $(48 \%)$ & 3 & $(60 \%)$ & 26 & $(55 \%)$ \\
\hline & Sub-Topic & 22 & $(35 \%)$ & 15 & $(65 \%)$ & 17 & (33\%) & 31 & (29\%) & 11 & $(44 \%)$ & 96 & $(36 \%)$ \\
\hline \multirow[t]{2}{*}{8} & Stra & 0 & $(0 \%)$ & 0 & $(0 \%)$ & 4 & $(80 \%)$ & 10 & $(48 \%)$ & 2 & $(40 \%)$ & 16 & $(34 \%)$ \\
\hline & pic & 0 & $(0 \%)$ & 0 & $(0 \%)$ & 15 & $(29 \%)$ & 31 & $(29 \%)$ & 7 & $(28 \%)$ & 53 & $(20 \%)$ \\
\hline \multirow[t]{2}{*}{9} & Strand & 0 & $(0 \%)$ & 0 & $(0 \%)$ & 1 & $(20 \%)$ & 6 & $(29 \%)$ & 0 & $(0 \%)$ & 7 & $(15 \%)$ \\
\hline & Sub-T & 0 & $(0 \%)$ & 0 & $(0 \%)$ & 6 & (12\%) & 33 & (31\%) & 0 & $(0 \%)$ & 39 & $(14 \%)$ \\
\hline \multirow[t]{2}{*}{10} & Strand & 0 & $(0 \%)$ & 0 & $(0 \%)$ & 2 & $(40 \%)$ & 5 & (24\%) & 1 & $(20 \%)$ & 8 & $(17 \%)$ \\
\hline & Sub-Topic & 0 & $(0 \%)$ & 0 & $(0 \%)$ & 4 & $(8 \%)$ & 19 & $(18 \%)$ & 7 & $(28 \%)$ & 30 & $(11 \%)$ \\
\hline \multirow[t]{2}{*}{ Kto10 } & Str & 10 & & 6 & & 5 & & 21 & & 5 & & 47 & \\
\hline & Sub-Topic & 62 & & 23 & & 51 & & 108 & & 25 & & 269 & \\
\hline
\end{tabular}

Generally, mathematics concepts at the lower elementary are taught using informal language which could be understood by the learners in their common language while the instruction at the upper elementary underwent a transition 
from informal to formal language to raise the level of understanding of mathematics concepts that are needed in high school. Mathematics at the high school level is taught with formal notations and is highly symbolic and structural as it equips learners with a more comprehensive set of mathematical concepts and higher-order thinking skills (Tanudjaya \& Doorman, 2020) that they need to either pursue the world of work or higher education.

Table 2 highlighted the LC per stage of the K to 10 mathematics which shows that NS and ME will be learned mostly by the students at the lower elementary level that served as the foundational knowledge, skills, and values needed in the other three content areas and higher grade level. The content topics of NS, ME, and GE areas are mostly with immediate practical applications in the daily life activities for the students, making it easier to relate the concept to daily life experiences, hence, providing them with the needed life skills.

Data also shows that high school learners are exposed to the more challenging LC of the GE, AL, and PS. This also implies that the upper elementary served as bridged from the informal instructions in lower elementary through the use of manipulative materials to a more formal and comprehensive set of instructions in high school level that equips the learner with a highly symbolic way of thinking and mathematical processes. This could be supported by the data in Table 3 where most of the content topics in high school are dominated by the AL content with Grade 7 has the highest percentage (55\% content strand and $36 \%$ sub-topics). Data also shows that the AL content area dominates the CT with 21 out of 47 content strands and 108 out of 269 sub-topics.

These spiral arrangements of the set of LC along with the organized CT are towards the attainment of the grade-level standards and KSS which will facilitate the learners manifest the twin goal of mathematics education: critical thinking and problem-solving skills. These two goals are to be achieved with a highly equipped and capable teachers in implementing the well-defined set of high-level skills and processes and desirable attitudes among the learners through the use of appropriate educational technologies and teaching pedagogies with due recognition to the different contexts of Filipino learners.

\section{Articulating Vertical Coherence of the K to 10 Mathematics Content Topics}

The content analysis of the KSS shows the vertical alignment of the CT and LC arranged in increasing complexity across grade levels. This section will discuss the specific details and characteristics of the CT coherence across grade levels. The curriculum mapping reveals that essential Mathematics CT along the five content areas is expected to be introduced informally in Kindergarten before entering Grade 1. Informal introduction of the CT usually happens in the early grade level of the lower elementary stage since learning activities are made with the use of models and/or concrete objects using the language of the learners and a situation familiar to them. The learner is therefore exposed to various mathematical tasks while playing and doing manipulative activities with models and concrete materials in the classroom as early as Kindergarten. 
Figure 3 illustrates how the sequencing of the content topics on Counting/Whole Numbers in NS are made from Kindergarten to Grade 7. Topics are introduced depending on what the learners have acquired such as order of operations in Grade 4 since learners acquired the skills on four fundamental operations in lower elementary. After reinforcements of the order of operations in Grade 5, exponents and square roots may be introduced (informal or formal) in Grade 6 and deepened in Grade 7 through reinforcements. A review of the lesson may be made after mastery for the deepening of skills.

\begin{tabular}{|c|c|c|c|c|c|c|c|c|c|c|c|}
\hline \multirow[b]{2}{*}{ Numbers and Number Sense Content Topic } & \multicolumn{11}{|c|}{ GRADE LEVEL } \\
\hline & $\mathbf{K}$ & 1 & 2 & 3 & 4 & 5 & 6 & 7 & 8 & 9 & 10 \\
\hline \multicolumn{12}{|l|}{ 1. Counting Numbers/Whole Numbers } \\
\hline \multicolumn{12}{|l|}{$\begin{array}{l}\text { 1.1 Conceptual understanding (including } \\
\text { reading, writing, and ordering) }\end{array}$} \\
\hline \multicolumn{12}{|l|}{$\begin{array}{l}\text { 1.2 The four basic operations (meaning, } \\
\text { properties, algorithms) }\end{array}$} \\
\hline \multicolumn{12}{|l|}{ 1.2.1 Addition } \\
\hline \multicolumn{12}{|l|}{ 1.2.2 Subtraction meaning and properties } \\
\hline \multicolumn{12}{|l|}{ 1.2.3 Multiplication meaning and properties } \\
\hline \multicolumn{12}{|l|}{ 1.2.4 Division meaning and properties } \\
\hline \multicolumn{12}{|l|}{ 1.2.5 Exponents and square roots } \\
\hline \multicolumn{12}{|l|}{ 1.2.6 Order of operations } \\
\hline \multicolumn{12}{|l|}{$\begin{array}{l}1.3 \text { Number Theory (factors, multiples, prime, } \\
\text { composite, and parity) }\end{array}$} \\
\hline \multicolumn{12}{|l|}{$\begin{array}{l}\text { 1.4 Problem-solving/ application to real-world } \\
\text { situations }\end{array}$} \\
\hline \multicolumn{12}{|l|}{ 1.5 Estimation and rounding off } \\
\hline \multicolumn{12}{|l|}{ 1.6 Roman Numerals } \\
\hline$\square$ Formal Introduction & & $\operatorname{Ret}$ & nfor & cem & & & & er & & & eview \\
\hline
\end{tabular}

Figure 3: A Sample Mapping of Content Topics in Numbers and Number Sense

The formal introduction of the content topic takes place when the teacher uses formal language and mathematical symbols and notations which usually happens beginning Grade 1 for foundational concepts and skills along with the five content areas of Mathematics. Ideally, depending on the level of difficulty of content topics are to be mastered by the learners in upper elementary (G4 to 6) and High school (G7 to 10) after the formal introduction and reinforcements of the prerequisite topics such as the ones illustrated in Figure 3. Reinforcements happen when the concept is re-introduced with more drills and practice exercises to help students deepen their understanding and rectify errors and misconceptions about the topic. Mastery of the content topics indicates that students demonstrate a solid understanding of the concepts and can execute the processes involved in doing mathematical tasks through further reinforcements. Moreover, a review of the CT and processes involved may be required so that learners can easily link the previous knowledge and skills to the new mathematics materials (SEI-DOST \& MATHTED, 2011).

The analysis on the vertical coherence of content topics of the $\mathrm{K}$ to 10 mathematics curriculum reveals the following themes showing both the strength and the areas for improvement: (1) vertical arrangements of the content topics, (2) placement of 
content topic of reinforcements, (3) teaching emphasis per grade level, (4) (de)congestion of $\mathrm{CT}$, and (5) integration and connection between and among content areas.

Vertical arrangements of CT. In consideration of the cognitive level of development of the learner, topics are arranged in increasing complexity from addition and subtraction of whole numbers in Grade 1 to multiplication and Division in Grade 2 going to order of operations in Grades 4 to 6 NS topics. The concept of the circle is first introduced through models, drawings, and construction in the Lower Elementary GE, introduced formally in Grade 5 GE with its basic parts, reinforced in Grades 6 to $7 \mathrm{ME}$, and mastered in Grade $10 \mathrm{GE}$ and AL as shown in Figure 4.

\begin{tabular}{|l|l|l|l|}
\hline Representation & Lower Elementary & Upper Elementary \\
\hline $\begin{array}{l}\text { Learning } \\
\text { competencies }\end{array}$ & $\begin{array}{l}\text { Draw and } \\
\text { describe a circle. }\end{array}$ & $\begin{array}{l}\text { Draw a circle with } \\
\text { different radii and } \\
\text { identify the basic parts of } \\
\text { the circle. } \\
\text { Derive the formula in } \\
\text { finding the circumference } \\
\text { (C=2 } \pi \mathrm{r}) \text { and area }\left(\mathrm{A}=\pi \mathrm{r}^{2}\right) \\
\text { of the circle. }\end{array}$ & $\begin{array}{l}\text { Sketch the graph of } \\
\text { a circle on the } \\
\text { coordinate plane } \\
\text { using center-radius } \\
\text { form: } \\
(\mathrm{x}-\mathrm{h})^{2}+(\mathrm{y}-\mathrm{k})^{2}=\mathrm{r}^{2} .\end{array}$ \\
\hline Content area & Geometry & $\begin{array}{l}\text { Geometry, } \\
\text { Measurement }\end{array}$ & $\begin{array}{l}\text { Geometry, } \\
\text { Patterns \& Algebra }\end{array}$ \\
\hline
\end{tabular}

Figure 4. Progression of Circle Representation

The sequence of the content topics also reveals the progression of the mathematical task and problem-solving activity which are arranged from simple to complex. The problem-solving task in Lower Elementary NS requires manipulation of whole numbers, the Upper Elementary NS problem solving may involve decimals and fractions, while the High School NS problem solving may involve rational numbers as well as integers. Teachers, therefore, need to be oriented with this sequencing of content topics to limit the scope of CT per stage or grade level. Mathematics high school teachers should not touch lessons on quadratic equations with complex numbers (non-real numbers) solution, e.g., $3 x^{2}+12=0$ with $\{ \pm 2 i\}$ as solution set.

However, the continuity of some concepts introduced to learners at the lower grade level is not visible on the next grade level such as the concept of multiplication and division which are introduced informally in kindergarten with a one-grade level gap since formal introduction happened in Grade 2 as illustrated in Figure 3. Discontinuity of the concepts introduced can be also observed in higher grade levels such as simplifying fractions in NS; time measures, mass measures, and conversion of units in ME; points, lines relationships, polygons, 
solids, and area measure in GE; patterns and polynomial concept in AL; and tables, graphs, and probability in PS.

In line with this scenario, the teacher-informants disclosed that they exercised their judgment in ordering the content topics and which mathematics content to cover based on the felt needs of the students. The Grade 9 Mathematics Teachers in Sorsogon Province reported that "The grade 9 teachers decide, as a group, to arrange the contents of the curriculum guide thinking that some topics (Prerequisite) should be discussed first before some other topics."

Placement of CT Reinforcements. The curriculum mapping reveals that there is an existence of CT (mostly in high school) that are introduced once only, with no reinforcement or deepening of skills for mastery in the next higher-grade level. This can be illustrated in Figure 5 where Geometry content topics and learning competencies on shapes are mostly undertaken at the high school level and are introduced only once such as congruence and similarity of the triangle, and special right triangles. These topics require a solid foundation of the competencies of $\mathrm{CT}$ in the lower years and require more reinforcements for deepening and mastery of skills as prerequisites in the study of Mathematics in the higher-grade level. This calls for a review of the geometry content (Abdullah \& Shin, 2019) of the current spiral progression mathematics curriculum to suit the need of students in developing 21st- century skills.

\begin{tabular}{|c|c|c|c|c|c|c|c|c|c|c|c|}
\hline \multirow{2}{*}{ Geometry Content Topic } & \multicolumn{11}{|c|}{ Grade Level } \\
\hline & $\mathbf{K}$ & 1 & 2 & 3 & 4 & 5 & 6 & 7 & 8 & 9 & 10 \\
\hline \multicolumn{12}{|l|}{ 2. Polygons } \\
\hline \multicolumn{12}{|l|}{ 2.1 Basic concepts (e.g., terms, classifications) } \\
\hline \multicolumn{12}{|l|}{$\begin{array}{l}\text { 2.2 Properties of polygons (e.g., number of } \\
\text { diagonals, angle sums) }\end{array}$} \\
\hline \multicolumn{12}{|l|}{2.3 Congruence } \\
\hline \multicolumn{12}{|l|}{ 2.4 Similarity } \\
\hline \multicolumn{12}{|l|}{2.5 Triangles } \\
\hline \multicolumn{12}{|c|}{ 2.5.1 Classification (according to sides and angles) } \\
\hline \multicolumn{12}{|c|}{$\begin{array}{l}\text { 2.5.2 Angles in a triangle (e.g., angle sum theorem, } \\
\text { exterior angle theorem) }\end{array}$} \\
\hline \multicolumn{12}{|l|}{ 2.5.3 Congruence } \\
\hline \multicolumn{12}{|l|}{ 2.5.4 Similarity } \\
\hline \multicolumn{12}{|l|}{ 2.5.5 Median, altitude, and angle bisector } \\
\hline \multicolumn{12}{|l|}{ 2.5.6 Triangle inequality } \\
\hline \multicolumn{12}{|l|}{ 2.5.7 Right triangles } \\
\hline \multicolumn{12}{|l|}{ 2.5.7.1 Pythagorean theorem } \\
\hline \multicolumn{12}{|l|}{ 2.5.7.2 Special right triangles } \\
\hline \multicolumn{12}{|l|}{ 2.5.8 Area } \\
\hline Legend: $\square$ Informal $\square$ Formal Introduction & & & & 15 & eme & nts & $\mathrm{Cor}$ & $\operatorname{ten}$ & 10 & & \\
\hline
\end{tabular}

Figure 5. A Sample Mapping of Content Topics in Geometry

The analysis of the curriculum reveals that the majority ( $83 \%$ or 223 out of 269 ) of the CT are introduced (informal or formal) only to the learners with no further reinforcements for mastery of the content in the higher grade level. Most of the CT reinforcements are along with NS (14 out of 62$)$, ME (12 out of 23), and GE (11 
out of 51) content areas which usually place in the upper elementary level. Very few (5 out of 108) of the CT in AL has teaching reinforcements, only in the elementary level, which shows that most of the high school AL content is introduced (informal or formal) once with no follow-up reinforcements.

Teaching Emphasis per Grade Level. Upon curriculum review and feedback from the teachers, the teaching emphasis of CT depends on first, the intent of the lesson, and second, the intent of the teacher. The intent of the lesson is guided by the expected LC that the learners need to execute at the end of the lesson whether it is for an informal or formal introduction, reinforcements, mastery, or review. It is expected for the learners to have mastery on the order of operations (introduced in Grade 5) by Grade 7 as reflected in the Mathematics Framework, however, the $\mathrm{K}$ to 10 Mathematics CG expects the mastery by Grade 6 since it was introduced already in Grade 4.

The teaching of congruence and similarity of polygons introduced in Grade 5 (informal or formal) is expected to be reinforced in Grade 6 level for mastery in Grades 7 and 8, and review in Grade 9. This concept was also introduced informally in kindergarten ME estimation and measuring. However, the CG reflects that this CT introduced in Grade 5 with the teaching reinforcement in Grades 8 (Triangle congruence) and Grade 9 (Triangle similarity) may not be enough to acquire mastery in a spiral progression curriculum. This is also true in the Plotting of points in the Cartesian Coordinate System of AL as reflected in the CG where students will formally learn the content topic in Grade 8 and reinforcements will just happen only in Grade 10. Feedback from an HS Teacher 3 in Gubat, Sorsogon reveals "Students lose mastery of the content since they find it hard to track the continuity of the mathematics contents from kinder to 10 especially if some competencies were not covered from the lower level."

The second form of teaching emphasis deals with the intent of the teacher based on their capability. A grade 7 teacher in Irosin, Sorsogon who teaches Mathematics for 24 years commented that "I am not so familiar with the new set of learning competencies under the K to 12 programs". The transition from focus to spiral content design brought some adjustments on the part of the Mathematics teacher since most of them taught one specific content area for several years and now they are obliged to teach all the five-content areas. Teaching emphasis of CT in the elementary level focuses along with the NS and ME content areas where they have acquired mastery in the previous curriculum design. There were features of skipping of lessons especially in the upper elementary along with AL, GE, and PS content area as disclosed by elementary teacher-informants since they were not so familiar with the CT.

The high school CT teaching emphasis depends on the learners' acquired mathematics competency. Teachers spend so much time on the review of the prerequisite topics to help students acquire the required mathematics skills on the least mastered competencies to ensure their readiness (Herrera \& Dio, 2016) on the new materials. The Grade 10 Teacher 3 in Sorsogon City observed that "... students do not have a strong foundation on the subject requisites." This scenario resulted in non-coverage of all the required LC along with the CT in the grade 
level when there are several observed learning deficiencies emanated in the lower grade level.

Mathematics teachers across grade levels should therefore be well oriented with the CT emphasis required per grade level so that appropriate classroom intervention can be made. However, limited teachers' understanding and use of the learning progression approach towards a vertically aligned curriculum implementation were observed (Jin, Mikeska, Hokayem \& Mavronikolas, 2019; Reeves \& McAuliffe, 2012).

Feedbacks from the informants reveal that training and orientations on the curricular reforms have not saturated the entire classroom teachers. Training and orientations provided were superficial, dealing only with the coverage and objectives of the curriculum, while content emphasis and the arrangement of topics across grade level were not tackled. A Teacher 3 in a remote area in Sorsogon City shares his experiences: "Back then, when I was given teaching assignment in Grade 7 Mathematics by our School Principal in SY 2013-2014, I was hesitant at first since I don't have the training yet. I only have a copy of the curriculum guide, teacher's material, and learners' material to study."

(De)Congestion of Content Topic. Upon careful review of the Mathematics Curriculum, there was K to 10 topics such as complex numbers in NS; maps scale in ME; skew and concurrent lines, Thales theorem, Transformations such as reflections, translations, rotations, symmetries in GE; and Historical development of algebra, midpoint of a line segment, parabola, special functions and operations of functions, systems of linear equations in three unknowns, quadratic relations, circular functions and trigonometry, and exponential and logarithmic functions in AL were removed for inclusion in the senior high school (G11 to 12). These decongestions imply that teachers should delimit the scope of the lesson according to the grade-level standards.

On the other hand, the K to 10 Mathematics Curriculum Guide has added CT along the five-content area that students are expected to learn. Some prerequisite CT included is factor tree, continuous division, GCF, LCM, and divisibility rule in learning number theory; attributes of objects in learning geometric shape and size; and basic concepts and importance of Statistics in learning measures of central tendencies and measures of variation. Other content topics added are necessary in acquiring the required mathematical skills such as ordinal numbers, place value of numbers, and money value in NS; Trigonometric Ratios, and solving problems involving right triangles, surveying, and navigation in AL; and measures of position in PS. These additions contribute to the congestions of the required CT in the $\mathrm{K}$ to 10 spiral mathematics curriculums.

With this, feedbacks from the teacher-informants reveals that students started to lose their mathematical interest when they reach the upper elementary level (Snider, 2004) because of the overloaded LC along with the five content areas. A Grade 8 Mathematics Teacher I in Masbate Province said that "The last quarter topics (usually Statistics and Probability) are not being discussed because of too many topics being covered in the entire school year." This scenario brought a significant 
impact on the ability of the students to learn the new concepts in the higher-grade level because of the unmastered competencies in the lower grade level. Another feedback from a Grade 7 Teacher I in Sorsogon City "Time allotted was not enough to cover all the learning competencies in the curriculum guide." It supported the claim that the coverage and congestion of the curriculum contribute to the low mastery of students on content and competencies as revealed by their performances in the Grade 6 and 10 Mathematics National Achievement Test (NAT) for the last three consecutive years (Albano, 2019).

Integration and Connection between and among Content Areas. The connection of topics between and among the Mathematics content area is one of the strengths identified in the current curriculum. Students cannot proceed to the study of the Pythagorean Theorem in Grade 9 GE without passing through the concept of square roots (Rational Numbers) in Grade 7 NS. Students cannot build their knowledge in finding the Distance between Two Points in Grade 10 GE without their previous knowledge of Cartesian Coordinate Plane in Grade 8 AL.

The mapping of competencies also shows strong integration of the CT among Mathematics content area such as the concept of parallel and perpendicular lines, Pythagorean Theorem, areas of two-dimensional figures, rational numbers, sets, among others which are repeatedly taught from one Mathematics content area to another. Figure 4 illustrates the integration and connection of the learning competencies among the content areas of GE, ME, and AL. This demonstrates that a strong integration among the Mathematics content area is necessary to be able to see the connections of the CT which is essential to the spiral progression design of the curriculum. Spiraling the contents exemplifies the idea that every mathematics concept relates to each other; and every mathematical task requires processes from simple to complex.

In summary, upon careful analysis of the curriculum through content and competency mapping, the good attributes of the Philippine Mathematics K to 10 Curriculum Guide shows that topics were arranged in increasing complexity with the corresponding parallel progression of the mathematical task and problemsolving activity. The curriculum illustrates integration and connection of topics between and among content areas which indicate strength and should be maintained in the curriculum. Research suggests learners learn mathematics more readily if topics and sub-topics are presented to them in ways that are conceptually connected over the school year (Reeves \& McAuliffe, 2012).

On the other hand, it was also found out that there was some discontinuity between the introduction (informal or formal) and teaching reinforcements of several CT. This scenario can contribute to the low mastery of the mathematical concepts and skills in a spiral progression approach where learners need to immediately utilize those acquired skills for mastery

Mathematics teachers, therefore, need to be oriented of this curriculum set-up and the corresponding consequence when integration and connection between and among the content areas are not emphasized, pre-requisites topics are not 
discussed, gaps between the introduction (formal or informal), and reinforcements are not minimized, and topics introduced are not reinforced. The findings of this study also imply that pre-service mathematics teachers need to be adequately trained in their content courses in a manner that is consistent with the spiral Mathematics K to 12 reforms (Mingus, 2002).

Vertical coherence of the content topics from kindergarten to Grade 10 has been identified not as the sole characteristic of a well-planned spiral progression approach of the curriculum. It also needs careful sequencing of learning competencies (Briggs \& Peck, 2015) according to the level of student cognitive development (Tran, Reys, Teuscher, Dingman \& Kasmer, 2016) with the provision of appropriate instructional technologies as suggested by the Master Teachers. Integration and connection of topics between and among the content areas capitalizing student prior experiences are necessary for the spiral curriculum design either for reinforcements and/or deepening of skills or for mastery. This approach also lessens the identified discontinuity of CT when properly implemented. This study does not claim that a vertically aligned curriculum causes high student achievement, but it is essential though not a sufficient ingredient in the recipe for greater student achievement (Roach, Niebling \& Kurz, 2008).

The curriculum mapping confirms the report of Mateo (2019) that there are a lot of competencies and content that the learners must study in a limited time allotted for each grade level. It was found out that the original plan of decongesting the curriculum through the enhanced basic education act of 2013 is not visible in the mathematics subject as revealed by the experiences of the basic education teachers in implementing the curriculum. Feedback from mathematics teacher-informants exposes that the allotted time for the teaching of the subject is insufficient to cover all the required set of learning competencies per grade level, especially in the upper elementary and high school level, which resulted in the skipping of the lessons. It is therefore recommended the revision of $\mathrm{K}$ to 10 curricula featuring the most essential learning competencies per content area where redundancies and gaps are minimized, and full utilization of the learning resources are optimized anchored on the international benchmarks.

\section{Conclusion}

The Philippine $\mathrm{K}$ to 10 Mathematics content topics and learning competencies were arranged in increasing complexity with the corresponding progression of the mathematical tasks per grade level. Strong integration and connection of topics between and among content areas were the identified strength of the curriculum. However, the Philippine spiral Mathematics basic education curriculum failed to decongest the distribution of the content and learning competencies across grade levels. The overcrowded mathematics curriculum with some identified gaps in the sequence and reinforcements of the topics along the five content areas became unrealistic to implement for general classrooms according to the level of cognitive development of Filipino learners. Execution of vertically aligned mathematics contents and standards from lower elementary to high school level which is necessary for attaining 21st-century skills among 
learners depends on teachers' readiness and understanding of the curriculum design. The $\mathrm{K}$ to 10 Mathematics curriculum needs revision covering the most essential learning competencies per content area aligned to the international standards. The provision of regular conduct of training and seminars as part of the professional development program for the mathematics teachers be conducted to have a full understanding and mindset readiness in the implementation of the $\mathrm{K}$ to 10 mathematics spiral curriculum design. This paper recommends to further explore the alignment of the set standards to the actual classroom practice as well as assessment practices.

\section{Acknowledgment}

The author is grateful to the Sorsogon State College Research and Extension Council for the guidance in the conceptualization of the research project, Ms. Kimberly Dig, for her time doing the clerical works during the entire duration of the study, and to all teacher-informants who willingly participated in the research process. The author also acknowledges the National Research Council of the Philippines (NRCP) for the publication grant.

\section{References}

Abdullah, A. H., \& Shin, B. (2019). A comparative study of quadrilaterals topic content in mathematics textbooks between Malaysia and South Korea. Journal on Mathematics Education, 10(3), 315-340. Retrieved from https:// files.eric.ed.gov/fulltext/EJ1229909.pdf

Ager, M. (2020, October 22). No study yet on poor PISA results; Gatchalian feels sorry for learners. Inquirer. net. Retrieved from https:// newsinfo.inquirer.net

Ahmad, J. (2011, October 25). Provus discrepancy evaluation model (DEM) [ppt]. Retrieved from https://www.slideshare.net

Albano, E. (2019, September 26). Grade 6 NAT Scores at 'low mastery' level. The Manila Times. Retrieved from https://www.manilatimes.net

Amer, A. (2006). Reflections on Bloom's revised taxonomy. Electronic Journal of Research in Educational Psychology, 4(1), 213-230. https://doi.org/10.25115/EJREP.V418.1217

Ari, A. (2011). Finding acceptance of Bloom's revised cognitive taxonomy on the international stage and in Turkey. Educational Sciences: Theory \& Practice, 11(2), 767-772. Retrieved from https://files.eric.ed.gov/fulltext/EJ927376.pdf

Bradley, L. H. (1985). The 10 indicators of effective curriculum development. Curriculum Leadership and development Handbook (pp. 141-146), Englewood Cliffs, N.J.: Prentice-Hall.

Briggs, D. C., \& Peck, F. A. (2015). Using learning progressions to design vertical scales that support coherent inferences about student growth, measurement. Interdisciplinary Research and Perspectives, 13(2), 75-99. https://doi.org/10.1080/15366367.2015.1042814

Burghes, D., \& Hindle, M. (2004). Response to key issues raised in the post-14 mathematics inquiry. International Journal of Mathematics Education in Science and Technology, 35(5), 633-660. https://doi.org/10.1080/00207390412331271230

Capilitan, D. B., Cabili, M. V., \& Sequete, F. R. (2015). A Review on the issues in the implementation of $\mathrm{K}$ to 12 science curriculums: $\mathrm{A}$ baseline study. https:// doi.org/10.13140/RG.2.2.10755.30249

Casayuran, M. (2020, February 10). Gatchalian: Curriculum reform needed for better PISA result. Manila Bulletin. $\quad$ Retrieved 
https:// mb.com.ph/2020/02/10/gatchalian-curriculum-reform-needed-forbetter-pisa-result/

Castillo, R. C. (2014). A paradigm shifts to outcomes-based higher education: Policies, principles, and preparations. International Journal of Sciences: Basic and Applied Research, 14(1), 174-186.

Department of Education (DepEd). (2016). Philippine K to 10 Mathematics Curriculum Guide. Retrieved from http://lrmds.deped.gov.ph

Drew, C. (2020). Bruner's spiral curriculum: The 3 key principles [Blog post]. Retrieved from https://helpfulprofessor.com/spiral-curriculum/

Ezeudu, F. O., Nkokelonye, C. U., \& Adigwe, J. C. (2013). Science education and challenges of globalization in the Igbo nation. US-China Education Review, 3(2), 116-127. Retrieved from https://files.eric.ed.gov/fulltext/ED540919.pdf

Glatthorn, A. A., Boschee, F., \& Whitehead, B. M. (2005). Curriculum Leadership: Development and Implementation. 2455 Teller Road, Thousand Oaks, CA 91320: Sage Publications.

Hale, J. A. (2008). A guide to curriculum mapping: Planning, implementing, and sustaining the process. Thousand Oaks, CA: Corwin Press.

Harden, R. M. (1999). What is a spiral curriculum? Medical Teacher, 21(2), 141-143. doi:10.1080/01421599979752

Hatzakis, T., Lycett, M., \& Serrano, A. (2007). A program management approach for ensuring curriculum coherence in IS (higher) education. European Journal of Information Systems, 16(5),

643-657. https://doi.org/10.1057/palgrave.ejis.3000707

Herrera, C., \& Dio, R. (2016). Extent of readiness of grade 10 students for general Mathematics of senior high school in Sorsogon City, Philippines. Asia Pacific Journal of Education, Arts, and Sciences, 3(4), 1-8. Retrieved from https://apjeas.apjmr.com/wp-content/uploads/2016/10/APJEAS 2016.3.4.01.pdf

Jacobs, H. H. (2004). Getting results with curriculum mapping. Alexandria, VA: Association for Supervision and Curriculum Development. Retrieved from https://eric.ed.gov/?id=ED489051

Jacobs, H. H., \& Johnson, A. J. (2009). The curriculum mapping planner: Templates, tools, and resources for effective professional development. Alexandria, VA: Association for Supervision and Curriculum Development.

Jensen, R. J. (1990). One point of view: The spring is wound too tight on our spiral curriculum. The Arithmetic Teacher, 38(1), 4-5. https://doi.org/10.5951/AT.38.1.0004

Jin, H., Mikeska, J., Hokayem, H., \& Mavronikolas, E. (2019). Toward coherence in the curriculum, instruction, and assessment: A review of learning progression literature. Science Education, 103, 1206-1234. https://doi.org/10.1002/sce.21525

Luft, J. A., Dubois, S. L., Nixon, R. S., \& Campbell, B. K. (2014). Supporting newly hired teachers of science: Attaining teacher professional standards. Studies in Science Education, 51(1), 1-48. doi:10.1080/03057267.2014.980559

Masters, K., \& Gibbs, T. (2007). The spiral curriculum: Implications for online learning. BMC Medical Education, 7, 52. https://doi.org/10.1186/1472-6920-7-52

Mateo, J. (2019, December 12). DepEd begins a review of the K-12 math curriculum. The Philippine Star. Retrieved from https:// www.philstar.com.

Mingus, T. (2002). A case study of spiraling content and pedagogy through core courses for pre-service secondary mathematics teachers. Readings in innovative ideas in teaching collegiate mathematics, 21-42. 
Morales, M. P. E. (2017). Transition and transformations in Philippine physics education curriculum: A case research. Issues in Educational Research, 27(3), 469-492. Retrieved from https://search.informit.com.au/documentSummary

Musa, S., \& Ziatdinov, R. (2012). Features and historical aspects of the Philippine educational system. European Journal of Contemporary Education, 2(2), 155-176. Retrieved from https://eric.ed.gov/?id=EJ1057820

National Council of Teachers of Mathematics. (2000). Principles and standards for school mathematics. Reston, VA: NCTM.

Nebres, B. F. (2009). Engaging the community, targeted interventions: achieving scale in basic education reform. Education Research Policy Practice, 8, 231-245. https:// doi.org/10.1007/s10671-009-9068-3

Okabe, M. (2013). Where does Philippine education go? The 'K to 12' program and Reform of Philippine basic education. Institute of Developing Economies (IDE) Discussion Paper No. 425 (pp. 1-30). Chiba: Institute of Developing Economies, JETRO. Retrieved from https://d1wqtxts1xzle7.cloudfront.net /40589215/ARRIDE_Discussion_No.425_okabe.pdf?

Philippine Republic Act No. 10533. (2013, May 15). Enhanced Basic Education Act of 2013. Retrieved from https://www.officialgazette.gov.ph /2013/05/15/republic-actno-10533/

Programme for International Student Assessment (PISA). (2018). PISA Results in Combined Executive Summaries, Volume I, II \& III. Paris: Organization for Economic Cooperation and Development (OECD). Retrieved from https://www.oecd.org/pisa/Combined_Executive_Summaries_PISA_2018.pdf

Provus, M. M. (1969). The Discrepancy Evaluation Model: An Approach to Local Program Improvement and Development. Retrieved from https://files.eric.ed.gov/fulltext/ED030957.pdf

Reeves, C., \& McAuliffe, S. (2012). "Is curricular incoherence slowing down the pace of school mathematics in South Africa? A methodology for assessing coherence in the implemented curriculum and some implications for teacher education". Journal of Education, 53, 9-36. http://hdl.handle.net/11189/3337

Roach, A. T., Niebling, B. C., \& Kurz, A. (2008). Evaluating the alignment among curriculum, instruction, and assessments: Implications and applications for research and practice. Psychology in the Schools, 45(2), 158-176. https://doi.org/10.1002/pits.20282

Schoenfeld, A. H. (1988). When good teaching leads to bad results: The disasters of 'well taught' mathematics courses. Educational Psychologists, 23(2), 145-166. https://doi.org/10.1207/s15326985ep2302_5

Schweitzer, K. (2020, February 11). Curriculum mapping: Definition, purpose, and tips [Blog post]. Retrieved from thoughtco.com/curriculum-mapping-definition4155236.

Shilling, T. (2013). Opportunities and challenges of curriculum mapping implementation in one school setting: Considerations for school leaders. Journal of Curriculum and Instruction, 7(2), 20-37. https://doi.org/10.3776/joci.\%25y.v7i2p20-37

Snider, V. E. (2004). A comparison of spiral versus strand curriculum. Journal of Direct Instruction, 4, 29-39. Retrieved from https://eric.ed.gov/?id=EJ755132

Science Education Institute- Department of Science and Technology (SEI-DOST), \& Philippine Council of Mathematics Teachers Educators (MATHTED, Inc. (2011). Mathematics framework for Philippine basic education. Manila: Author.

Smith, A. (2004). Making Mathematics Count: The Report of Professor Adrian Smith's Inquiry into Post-14 Mathematics Education. London: The Stationary Office. Retrieved from http://www.mathsinquiry.org.uk/report/MathsInquiryFinalReport.pdf 
Suter, W. N. (2012a). Qualitative research defining and designing. Introduction to educational research: A critical thinking approach, 2, 1-10.

Suter, W. N. (2012b). Qualitative data, analysis, and design. Introduction to educational research: A critical thinking approach, 2, 342-386. https://dx.doi.org/10.4135/9781483384443.n12

Tanudjaya, C. P., \& Doorman, M. (2020). Examining higher-order thinking in Indonesian lower secondary mathematics classrooms. Journal on Mathematics Education, 11(2), 277-300. Retrieved from https:/ / files.eric.ed.gov/fulltext/EJ1252003.pdf

Tran, D., Reys, B. J., Teuscher, D., Dingman, S., \& Kasmer, L. (2016). Analysis of Curriculum Standards: An Important Research Area. Journal for Research in Mathematics Education, 47(2), 118133. https:// doi.org/10.5951/jresematheduc.47.2.0118

Van den Akker, J. (2004). Curriculum perspective: An introduction. In: Curriculum Landscape and Trends. Springer, Dordrecht. https://doi.org/10.1007/978-94017-1205-7_1

Verzosa, D. M. B., \& Vistru-Yu, C. P. (2019). Prospects and challenges in implementing a new mathematics curriculum in the Philippines. In C. Vistru-Yu \& T. Toh, (Eds) School Mathematics Curricula. Mathematics Education - An Asian Perspective. Singapore: Springer. https:// doi.org/10.1007/978-981-13-6312-2_11

Vidali, E. L., \& Adams, L. D. (2006). The challenges of globalization. Changes in Education Policy and Practice in the Greek Context, Childhood Education, 82(6), 358-362. https://doi.org/10.1080/00094056.2006.10522862 